\title{
Autoantibodies in systemic autoimmune diseases: specificity and pathogenicity
}

\author{
Jolien Suurmond and Betty Diamond \\ Center for Autoimmune and Musculoskeletal Diseases, Feinstein Institute for Medical Research, North Shore-LIJ, Manhasset, New York, USA.
}

\begin{abstract}
In this Review we focus on the initiation of autoantibody production and autoantibody pathogenicity, with a special emphasis on the targeted antigens. Release of intracellular antigens due to excessive cell death or to ineffective clearance of apoptotic debris, modification of self-antigens during inflammatory responses, and molecular mimicry contribute to the initiation of autoantibody production. We hypothesize that those autoreactive B cells that survive and produce pathogenic autoantibodies have specificity for self-antigens that are TLR ligands. Such B cells experience both B cell receptor (BCR) activation and TLR engagement, leading to an escape from tolerance. Moreover, the autoantibodies they produce form immune complexes that can activate myeloid cells and thereby establish the proinflammatory milieu that further negates tolerance mechanisms of both $B$ and $T$ cells.
\end{abstract}

\section{Introduction}

The first autoantibodies were discovered in the late 1940s, when both antinuclear antibodies (ANAs) and rheumatoid factors (RFs) were described as serum factors that could bind nuclear antigens and immunoglobulins, respectively $(1,2)$. ANA and RF were recognized as diagnostic features of systemic lupus erythematosus (SLE) or RA, respectively, and as contributors to disease pathogenesis. It is now becoming increasingly clear that autoantibodies play a pivotal role in the pathogenesis of many diseases and that autoantibodies mediate both systemic inflammation and tissue injury (3).

Here we focus mainly on the autoantibodies associated with the autoimmune diseases SLE and RA, and we discuss the recent developments on the generation of autoreactivity and the contribution of these antibodies to disease pathogenesis. We propose a model in which autoreactive B cells escape from tolerance because they bind TLR ligands and undergo clonal expansion because of continuous exposure to antigen. Furthermore, the generation of immune complexes containing TLR ligands leads to systemic inflammation through the activation of innate immune cells. This systemic inflammation is part of the disease process and further impairs tolerance mechanisms. While we cite data from studies of SLE and RA to support this paradigm, we believe the model has broader applications.

\section{Central versus peripheral tolerance defects}

During B cell development in the BM, autoreactivity is prevented through receptor editing, apoptosis, and induction of anergy in $\mathrm{B}$ cells expressing an autoreactive $\mathrm{B}$ cell receptor (BCR). When immature B cells express surface $\operatorname{IgM}$, recognition of a selfantigen in the BM can induce these processes. Transitional B cells emerging from the $\mathrm{BM}$ continue to mature in the spleen, where additional tolerance mechanisms are in place. The exact mechanisms in this peripheral compartment are not fully understood,

Conflict of interest: Betty Diamond owns stock in Macrogenics and receives research support from Merck-Serono.

Reference information: J Clin Invest. 2015;125(6):2194-2202. doi:10.1172/JCI78084. but they require ligand recognition by the $\mathrm{BCR}$, similar to the tolerance checkpoints in the BM (4). After this stage, mature naive $\mathrm{B}$ cells can be activated upon antigen recognition, allowing them to enter the germinal center (GC). The GC is a site of rapid clonal expansion of B cells, affinity maturation, class switching, and differentiation to memory B cells or plasma cells. A unique feature of GC-matured B cells is that they have undergone extensive somatic mutation of the antibody genes. As somatic hypermutation can give rise to de novo autoreactivity as well as enhance affinity of existing autoreactive B cells, additional tolerance checkpoints in the post-GC compartment have been suggested to effectively prevent autoreactivity in memory B cells and plasma cells, through either apoptosis or receptor editing $(5,6)$.

The ability to sequence and clone Ig genes from individual B cells has opened the opportunity to study these tolerance checkpoints in health and disease. The results from such studies using B cells from healthy individuals suggest that a high number of autoreactive $\mathrm{B}$ cells is generated in the $\mathrm{BM}$ and that sequential tolerance checkpoints lead to a gradual decrease in autoreactivity as the B cells mature (7).

The presence of autoreactive B cells in healthy individuals indicates that central tolerance is not sufficient to remove all autoreactive $\mathrm{B}$ cells with self-targeting BCRs. Indeed, it is well-established that both the B1 subset and marginal zone B subset contain high numbers of autoreactive $\mathrm{B}$ cells, and in animal models $\mathrm{B}$ cells from these subsets can give rise to pathogenic autoreactivity (8-10). Although defects in early B cell tolerance have been found in patients with autoimmune disease $(11,12)$, current data suggest that most of their autoreactive $B$ cells are derived from nonautoreactive precursors. Autoantibodies derived from memory B cells in systemic autoimmune disease are often class-switched and highly somatically mutated, which suggests that they have been involved in GC reactions (13-19). Memory B cells making anti-DNA antibodies and anticitrullinated protein antibodies (ACPAs) in patients with autoimmune disease are thought to be derived from nonautoreactive precursors because back-mutation of their somatic mutations 
Table 1. Autoantibody recognition in systemic autoimmune disease

\begin{tabular}{|c|c|c|c|c|}
\hline Antigen location & Antibody & Antigen & Disease & PRR recognition \\
\hline \multirow[t]{5}{*}{ Nuclear } & Anti-Ro (SS-a) & Ro-RNP complex & SLE, Sjögren's syndrome & TLR7 \\
\hline & Anti-La (SS-B) & La antigen & SLE, Sjögren's syndrome & TLR7 \\
\hline & Anti-Sm & Small nuclear RNP & SLE & TLR7 \\
\hline & Anti-histone & Histones & SLE (drug-induced) & TLR2 and TLR4 \\
\hline & Anti-Scl-70 & Topoisomerase I & Systemic sclerosis & \\
\hline & ACA & Cardiolipin & Antiphospholipid syndrome, SLE & NLRP3 \\
\hline \multirow[t]{2}{*}{ Modified proteins } & ACPA & Citrullinated proteins & RA & TLR4 \\
\hline & Anti-Carp & Carbamylated proteins & RA & \\
\hline \multirow[t]{2}{*}{ Extracellular } & RF & $\mathrm{RF}(\operatorname{IgC})$ & RA & \\
\hline & $\begin{array}{l}\text { Lupus anticoagulant } \\
\alpha 3 \text { Chain of basement membrane } \\
\text { collagen (type IV collagen) }\end{array}$ & $\begin{array}{c}\text { Phospholipids } \\
\alpha 3 \text { Chain of basement membrane } \\
\text { collagen (type IV collagen) }\end{array}$ & $\begin{array}{l}\text { Antiphospholipid syndrome } \\
\text { Coodpasture's syndrome }\end{array}$ & TLR4? \\
\hline
\end{tabular}

ACA, anti-cardiolipin antibody.

to germline sequences removes their autoreactivity $(17,18)$. Furthermore, although naive polyreactive B cells can recognize citrullinated proteins or DNA and therefore could give rise to ACPAs and anti-DNA-producing plasma cells, the affinity of ACPAs and antiDNA antibodies from naive $B$ cells is greatly reduced compared with antibodies in patient serum, suggesting that these naive B cells have undergone affinity maturation before developing into plasma cells $(11,18)$. While sequence analyses of autoantibodies have thus far only been performed for a limited number of patients and access to plasma cells is limited by the unavailability of BM samples, there is consistent evidence that many autoreactive B cells in autoimmune disease mature in the GC.

Taken together, these data suggest that defects in central and early peripheral tolerance checkpoints are present in autoimmune disease patients, but the defects in early tolerance checkpoints do not necessarily lead to the generation of pathogenic autoantibodies. As studies point to an important role of somatic hypermutation during GC reactions as a source of autoreactivity, post-GC checkpoints are likely defective in patients with autoimmune disease, but our understanding of these checkpoints is limited.

\section{T cell help for autoantibody production}

Development of high-affinity antibodies requires cognate $\mathrm{B}$ cell/T cell interactions to initiate and sustain the GC. Somatically mutated autoantibodies in autoimmune disease are thought to be derived through $\mathrm{T}$ cell-dependent pathways, especially because the presence of autoantibodies is often correlated with the presence of specific HLA alleles $(20,21)$. However, at present little is known about the specificity of $\mathrm{T}$ helper cells that are able to stimulate autoantibody-producing B cells.

The most direct pathway for $\mathrm{T}$ cell helper function is for $\mathrm{T}$ cells to recognize the same antigen as the B cells. In RA, one of the genetic risk HLA alleles, HLA-DRB1 ${ }^{\star} 0401$, has recently been associated with presentation of citrullinated peptides, allowing for activation of citrulline-specific T cells (22). These T cells may engage in direct antigen-specific interactions with ACPA-producing B cells when citrullinated antigens are internalized through BCR-dependent recognition. However, the $\mathrm{T}$ cell specificities involved in the activation of other autoreactive B cells, such as DNA-reactive B cells, are not known. Some studies suggest that the epitopes for B cells and T cells do not necessarily need to be the same. For example, B cells can internalize multimolecular complexes through BCR-mediated recognition and can then process peptides from different proteins present in the complex. This internalization of multimolecular complexes clearly enables processing of nucleoproteins capable of binding DNA in lupus-prone mice and SLE patients (23-26).

$\mathrm{T}$ cell help for autoantibody-producing B cells can also originate from $\mathrm{T}$ cell responses to foreign antigens through molecular mimicry between viral or bacterial antigens and self-antigens (27-30). Activation of nonautoreactive $\mathrm{T}$ cells by foreign antigens can lead to activation of $\mathrm{B}$ cells that recognize the foreign antigen but also cross-react with a self-antigen (31). It is hypothesized that such activation can lead to selection and maturation of high-affinity self-reactive B cells.

In addition to the typical GC response, class switching and somatic hypermutation can also occur outside of the classical GCs. In several autoimmune diseases, ectopic lymphoid structures can develop, usually in the target organ, such as the synovial tissue in RA or the kidney in SLE. These structures closely resemble the GC with the presence of $\mathrm{B} / \mathrm{T}$ lymphoid clusters that include $\mathrm{T}$ follicular helper cells and follicular dendritic cells. Ectopic lymphoid organs are often associated with the production of high levels of autoantibodies, suggesting that local activation of these cells can contribute to T cell-dependent B cell differentiation, as in the GC $(32,33)$.

\section{Target antigens for autoantibodies}

Autoantibodies can be directed against a variety of molecules, such as nucleic acids, lipids, and proteins, and these target antigens can be located in the nucleus or cytoplasm, on the cell surface, or in the 


\section{A}

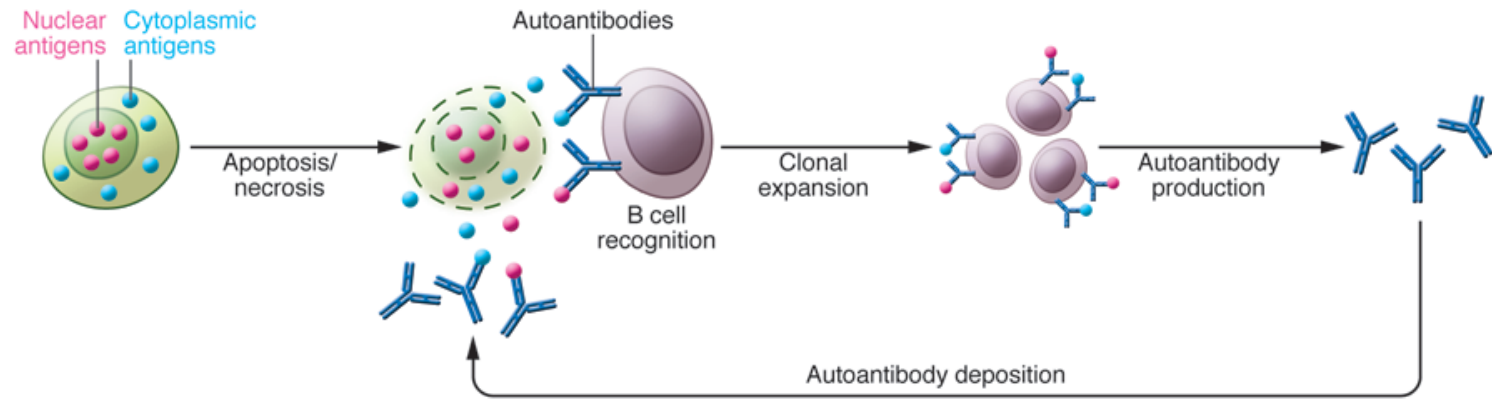

B
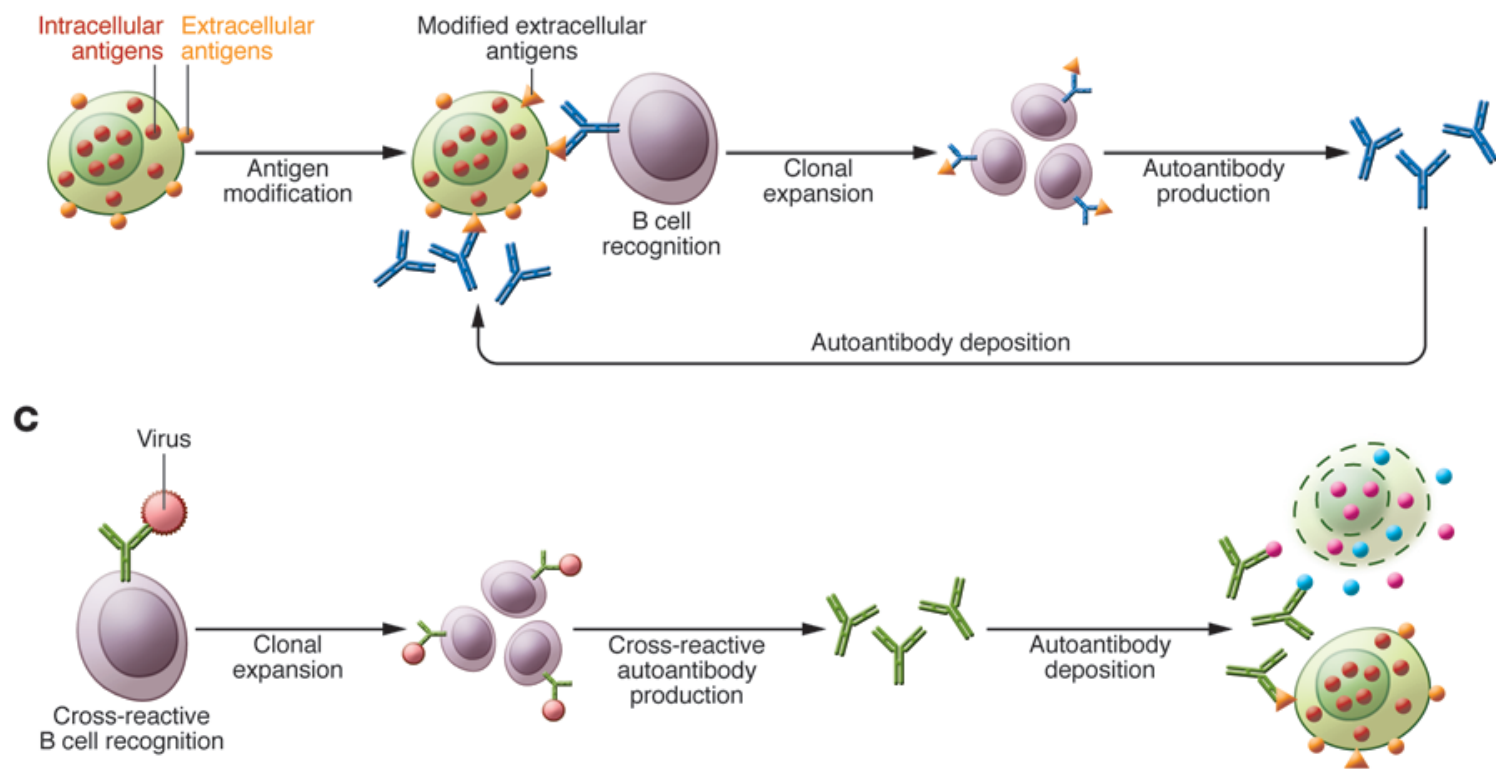

Figure 1. Mechanisms for autoantibody production: apoptosis, antigen modification, and cross-reactivity. Three models can explain the recognition of intracellular antigens by autoantibodies. (A) Cell death through apoptosis or necrosis leads to extracellular exposure of intracellular self-antigens through release of intracellular contents into the extracellular environment, formation of apoptosis blebs, or NETosis. If clearance mechanisms are insufficient, there may be recognition of these antigens by $B$ cells and autoantibody production. (B) Modification of self-antigen generates neoantigens, to which $B$ cells have not been tolerized. (C) Autoantibody production arises from responses to foreign antigens, which cross-react with self-antigens.

extracellular milieu. When analyzing autoantibodies in the most common systemic autoimmune diseases, it is striking that most of them target ubiquitously expressed intracellular molecules (Table 1). Among these, ANAs, a group of heterogeneous antibodies targeting multiple distinct nuclear components, are the most common. The molecules recognized by ANAs are normally present in the nucleus and therefore are not accessible to antibodies or $\mathrm{B}$ cells. It is only in conditions of cell death that nuclear contents are released into the extracellular environment.

RA can be considered an exception, as the autoantibodies in RA do not generally target intracellular molecules. The classical example is RF, which recognizes the Fc portion of IgG, an abundant protein in serum. Another important group of autoantibodies in RA targets modified proteins, with ACPAs being the best characterized. ACPAs show a very high specificity in clinical diagnostics for RA and are present in the majority of patients with RA. These antibodies recognize a variety of proteins such as fibrinogen or fibrin, vimentin, type II collagen, $\alpha$-enolase, and histones that have undergone a posttranslational modification in which citrulline is substituted for arginine $(34,35)$. Most of these antigenic citrullinated antigens are extracellular proteins, although intracellular citrullinated proteins have also been identified as targets of ACPAs. To date, it is unknown whether intracellular or extracellular citrullinated antigens are the main driver of the ACPA response.

\section{B cell propagation in response to self-antigen or foreign antigen}

The intracellular location of many autoantibody targets raises the question of how these antigens can drive clonal expansion, a process that requires the recognition of antigens through the BCR, which occurs in the extracellular space.

Two main hypotheses exist that can explain how autoantibodies arise that recognize intracellular self-antigens (Figure 1A). The first theory proposes that apoptosis plays an important role as a source of nuclear and cytoplasmic self-antigens. During this process of programmed cell death, apoptotic blebs appear on the cell surface and microparticles can be released from the cell, both of which contain several cytoplasmic and nuclear components. These include several 

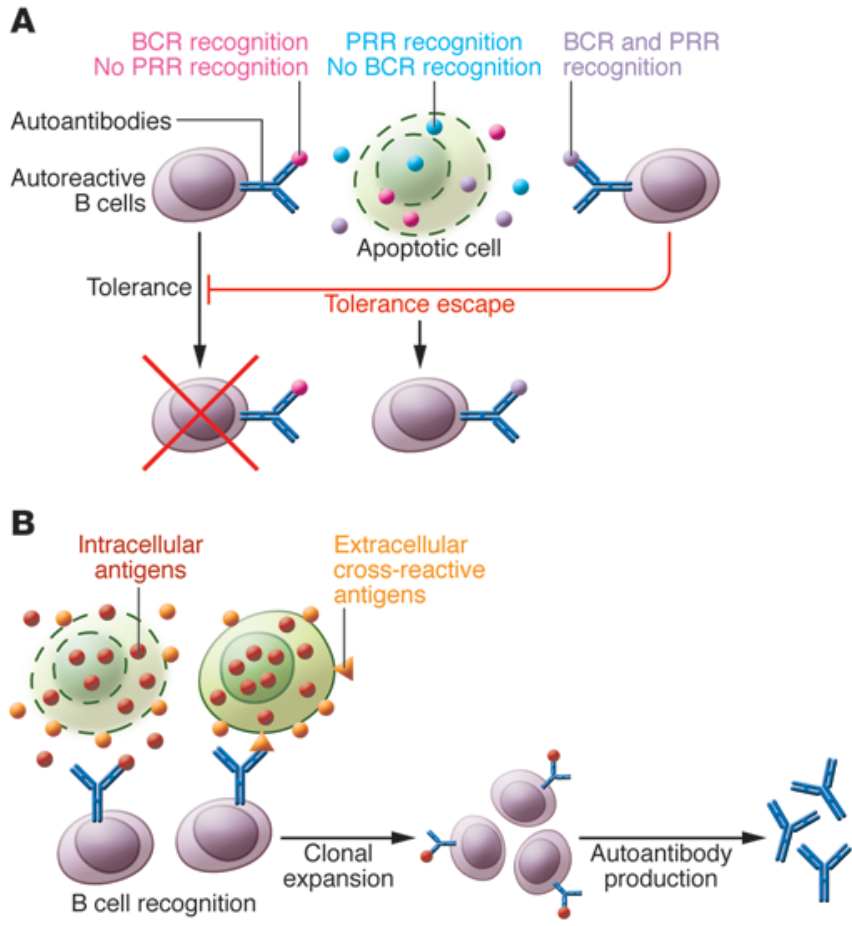

Figure 2. Proposed role of PRR activation and cross-reactivity in expansion of autoreactive $B$ cells and their effector functions. (A) Self-antigens that bind PRRs can activate B cells. We hypothesize that the combined recognition of self-antigens by BCRs and PRRs is required for tolerance escape in autoreactive B cells. (B) B cells require recognition of antigen through their BCR for clonal expansion. As most autoantibodies recognize intracellular self-antigens, cross-reactivity to cell surface or extracellular molecules enhances clonal expansion and differentiation into memory and plasma cells.

of the intracellular antigens recognized by autoantibodies, such as histones, dsDNA, RNA, ribonucleoproteins (RNPs), and myeloperoxidase and proteinase 3 in neutrophils (36-39). Furthermore, the process of apoptosis induces several modifications in the nucleus, including histone citrullination and acetylation, which can be recognized by autoantibodies in RA and SLE, respectively (40, 41). Apoptotic blebs are normally quickly engulfed by phagocytes to prevent immune activation (42); however, a failure to do this, due either to a genetic defect in one of the apoptosis clearance pathways (as often seen in autoimmune disease) or to excessive release of these blebs due to inflammation, allows for the sustained presence of these self-antigens in the extracellular environment (43).

Another pathway for propagation of autoantibody responses toward intracellular antigens is through cross-reactivity with extracellular antigens. An example of such cross-reactivity is antidsDNA antibodies in SLE, which have been shown to recognize antigens in the glomerular basement membrane, where these autoantibodies can deposit (44-47). While the binding of some anti-dsDNA antibodies to glomeruli depends on the presence of nucleosomes containing DNA on the glomerular membrane, the contribution of cross-reactivity to renal pathology has also been demonstrated $(48,49)$.

In RA, ACPAs can target both intracellular and extracellular citrullinated antigens that arise during an inflammatory response (Figure 1B and refs. 34, 35, 50). It has not been for- mally shown, but it is likely that the citrulline epitopes on different antigens form the basis for cross-reactivity between intraand extracellular antigens. In cardiomyopathy, autoantibodies targeting cardiac myosin, an intracellular antigen, have been shown to cross-react with the $\beta$-adrenergic receptor, thereby inducing stimulation of cardiomyocytes. These findings suggest that cross-reactivity between intra- and extracellular antigens can drive clonal expansion.

Similarly, cross-reactivity between foreign antigens and self-antigens can drive the expansion of autoreactive B cells (Figure 1C). Several autoantibodies exhibit such cross-reactivity: dsDNA autoantibodies cross-react with pneumococcal bacteria and Epstein-Barr virus $(29,45)$ and anti-neutrophil cytoplasm antibodies (ANCAs) recognize the bacterial adhesin FimH (28). However, this cross-reactivity between foreign antigens and intracellular self-antigens still requires the release of intracellular antigens through apoptosis or cross-reactivity to surface antigens in order for autoantibodies to bind and exert their pathogenic activity.

We speculate that B cells with BCRs that recognize only intracellular antigens will propagate less well than those that crossreact with more ubiquitous cell surface or extracellular antigens. Therefore, the basis for clonal expansion of many autoreactive $\mathrm{B}$ cells can be found in their cross-reactivity.

\section{TLR recognition and its role in escape from tolerance}

Many antigens recognized by autoantibodies are able to trigger pattern recognition receptor (PRRs), including TLRs and NodLike receptors (NLRs). These receptors are listed in Table 1 and include DNA, RNA, citrullinated fibrinogen, cardiac myosin, cardiolipin, and oxidated phospholipids (51-56).

$B$ cells express several TLRs for nucleic acids, including TLR7 and TLR9. Engagement of these TLRs activates B cells. Notably, many antigens recognized by autoantibodies are ligands for B cell TLRs (Table 1), suggesting a role for TLR recognition in the breakdown of tolerance against these antigens. Indeed, mice deficient in TLR7, TLR9, or the TLR-associated signaling adaptor MyD88 are partially protected against development of ANAs and lupus-like symptoms (57-60). This protection derives from the effects that TLR ligation has on reducing $B$ cell tolerance.

Combined BCR and TLR ligation by nuclear antigens has been shown to induce a synergistic signaling response, mediated by colocalization of TLR9 and antigen internalized through BCR (61-63). Thus, self-antigens able to activate endosomal TLRs and BCRs will induce robust activation in B cells. Some studies suggest that TLR activation of immature B cells can dysregulate central tolerance pathways (64-66). We hypothesize that TLR ligation might also explain the failure of peripheral tolerance in autoimmune disease. Several studies show increased TLR expression and function in activated or memory B cells compared with immature B cells, allowing for robust activation through TLR in the GC (67-70). As tolerance in the GC is thought to be driven by a survival advantage through affinity-driven selection, combined $\mathrm{BCR} / \mathrm{TLR}$ ligation in the GC may facilitate positive selection and escape from tolerance. 


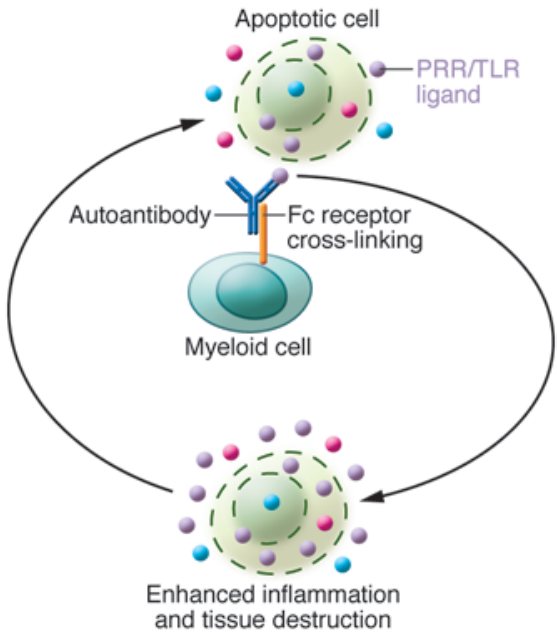

Figure 3. The role of PRR activation by self-antigens in autoantibody pathogenesis. During autoimmune responses, inflammation can lead to cell death and release of endogenous PRR or TLR ligands. When recognized by autoantibodies, these ligands can activate myeloid immune cells through both Fc receptors and PRRs, leading to an enhanced inflammatory response. This response, in turn, can lead to tissue destruction and release of ligands for PRRs and autoantibodies, which further amplifies the chronic inflammatory response.

\section{TLR engagement and T cell-independent B cell activation}

Increased levels of the cytokine B cell-activating factor of the tumor necrosis factor family (BAFF) and TLR activation have been implicated in T cell-independent activation of autoreactive B cells (60, 71). In vitro, increased TLR activation and BAFF levels have been shown to trigger activation-induced cytidine deaminase expression, which also induces somatic hypermutation and class switching in naive B cells (72). Another study showed that neutrophilderived cytokines including BAFF can induce somatic hypermutation and class switching in marginal zone B cells (73). Furthermore, several studies showed that TLR activation can directly instigate IgG class switching and $\mathrm{T}$ cell-independent plasma cell differentiation, thereby possibly circumventing the requirement for $\mathrm{T}$ cell help in the peripheral compartment $(57,74,75)$.

It is not clear whether these $\mathrm{T}$ cell-independent $\mathrm{B}$ cell activation pathways are sufficient to induce the levels of somatic hypermutation that are observed in autoreactive $\operatorname{IgG}^{+}$memory $\mathrm{B}$ cells. Importantly, TLR activation and T cell help might interact to induce somatic mutation. TLR activation of B cells can enhance antigen presentation and increase surface expression of co-stimulatory molecules, which will facilitate non-antigen-specific interaction with $\mathrm{T}$ cells $(76,77)$. Therefore, TLR activation can enhance somatic mutations in $\mathrm{T}$ cell-dependent or -independent B cell responses.

Together, these data support an important role for TLR activation in the development of autoantibody responses, especially when activated in combination with BCRs. B cells with BCR specificity for a TLR ligand may be enabled to escape tolerance mechanisms. If such a BCR binds a ubiquitous antigen, such as a cell membrane or extracellular antigen, clonal expansion occurs, with affinity maturation and differentiation to a plasma cell (Figure 2, A and B).

\section{Pathogenicity of autoantibodies}

The pathogenicity of autoantibodies has been extensively debated. Proof of pathogenicity is derived from the ability of autoantibodies to induce cellular damage or immune activation in vitro or to passively transfer autoimmune disease in animal models, as well as the effectiveness of B cell-targeting therapies. Although such evidence is not established in all autoimmune diseases, the most common systemic autoantibodies, such as ANAs and ACPAs, are considered pathogenic.

Pathogenicity has been most thoroughly studied in mouse models with lupus-like disease. Several studies have shown that passive transfer of anti-DNA antibodies or expression of autoreactive transgenic BCRs can cause inflammation in the kidneys, although not all antibodies have equal capacity to do so (78-80). In contrast, only limited evidence of the pathogenicity of ACPAs or RF is present in mouse models of arthritis. This may be due to the absence of these autoantibodies in most mouse models; however, when ACPAs are adoptively transferred into mice with lowlevel inflammation caused by anti-collagen antibodies, ACPAs enhances arthritis, directly implicating them in the inflammatory process in the joint $(80,81)$.

\section{Autoantibody effector functions}

The effector functions that are employed by autoantibodies resemble those of antibodies in general and are therefore largely dependent on their isotype. Specific autoantibody isotypes are present in different diseases, with IgA antibodies present in antiphospholipid syndrome and IgE autoantibodies present in SLE (82-84). IgM and IgG autoantibodies are the most abundant. IgM autoantibodies are also present in healthy individuals and are therefore often considered to be less pathogenic (85). IgM is a potent activator of the complement component 1 , q subcomponent (C1q), which has recently been shown to inhibit TLR activation by acting as a ligand for the inhibitory leukocyte-associated immunoglobulin-like receptor 1 (LAIR1), suggesting that IgM might inhibit immune effector responses (86). In support of this model are experiments that showed that an inability to secrete IgM in B cells leads to IgG autoantibody production in mice (87).

A major pathway for immune activation and tissue damage for systemic autoantibodies is through formation of immune complexes. In situ immune complexes form when antigen is present at specific sites within tissues. Different monoclonal anti-DNA antibodies have distinct patterns of renal deposition, depending on their specificity and cross-reactivity (45). Although RA is associated with the presence of circulating immune complexes, the disease is mainly limited to the joints. This is thought to arise in part from preferential binding of antibodies to citrullinated proteins present in the synovium (88).

Immune complexes formed in situ can activate the complement system and Fc receptors, leading to tissue inflammation and damage. Complement activation by autoantibodies has been shown to occur through both classical and alternative pathways $(89,90)$ and can lead to direct cell lysis and damage as well as recruitment of leukocytes to further enhance inflammatory responses. Complement-mediated cell lysis has also been shown to serve as a source of antigen, such as DNA, RNP, and citrullinated proteins (91). 
Activating Fc receptors are expressed by a variety of cells, particularly by immune cells of the myeloid lineage. Autoantibodies have been shown to activate these immune cells through Fc $\gamma$ R-dependent pathways (92-94). In vivo, Fc $\gamma$ R-deficient mice often show decreased autoimmunity $(95,96)$. The capacity of IgG to activate Fc receptors contributes to their increased pathogenicity compared with IgM autoantibodies. However, IgM-RF was recently shown to enhance Fc $\gamma \mathrm{R}$-dependent activation by ACPAs, demonstrating that isotypes other than IgG can contribute to pathogenesis (97).

\section{Clinical evidence for autoantibody pathogenesis}

Most autoantibodies are present years before disease onset and thus are not merely a consequence of inflammation (98-100). Furthermore, for ACPAs, there is evidence for epitope spreading, affinity maturation, isotype switching, and glycosylation changes before clinical symptoms start. Each of these changes is associated with greater pathogenic potential (101-105). In addition to the changes in the intrinsic properties of autoantibodies before disease onset, the target organ can also become susceptible to autoantibody deposition or binding. This is in accordance with the multiple-hit theory of autoimmunity, in which genetic and environmental factors induce an initial break in tolerance leading to production of autoantibodies. A "second hit" is needed for the antibody to exert pathogenic effects and to sustain the inflammatory cascade of the autoimmune response. This phenomenon is perhaps most clearly illustrated in myositis, in which the autoantibodies bind regenerating myocytes and thus sustain a cycle of injury and regeneration (106).

\section{Chronic inflammation}

As stated above, many autoantibodies target ubiquitously expressed intracellular molecules. For antibodies to bind these targets, these antigens need to be released to the extracellular environment, where antibodies or immune complexes are deposited. As the self-antigens are ubiquitously present, autoantibody effector mechanisms fail to eliminate the antigen, causing inflammatory injury to tissues that leads to additional release of these intracellular antigens. This process causes a vicious cycle wherein each disease flare can initiate further autoantibody production and tissue injury (107-109). Furthermore, combined TLR- and Fc receptor-mediated activation of myeloid cells often leads to an enhanced inflammatory response that is thought to contribute to the chronicity of inflammation $(51,94,110,111)$. Therefore, those self-antigens that can most potently activate B cells because they are TLR ligands may also potently enhance pathogenic inflammatory responses (Figure 3).

\section{Conclusions}

A break in tolerance against self-antigens or modified self-antigens can lead to the production of autoantibodies. Such a breach in tolerance can originate from a lack of clearance of apoptotic debris, inflammation-mediated modification of self-antigen, or cross-reactivity between foreign and self-antigens. Some autoantibodies cross-react between an intracellular antigen that is a TLR ligand and cell surface or extracellular antigen, allowing for continued B cell activation and autoantibody-mediated injury. After initiation of autoantibody production, inflammation may cause release of intracellular or modified self-antigens, leading to antibody effector function and instigation of clinical symptoms as well as to the propagation of the autoreactive B cell clones. These pathogenic processes are mainly mediated by IgG autoantibodies, although other isotypes may contribute. TLRs play an important role during both initiation and pathogenesis of autoantibody responses, as they can recognize several selfantigens such as alarmins. TLR activation can enhance the initiation of autoantibody responses and can synergize with Fc-mediated effector functions. We speculate that those autoreactive B cells that can escape tolerance and expand and differentiate in response to antigen have BCRs that bind antigens that associate with or are TLR ligands. Reactivity with abundant cell surface or extracellular antigens permits the clonal expansion and survival of these B cells once inflammation has subsided. Furthermore, this cross-reactivity may contribute to their pathogenicity.

\section{Acknowledgments}

This work was supported by NIH grant 5R01AR057084-05.

Address correspondence to: Betty Diamond, Center of Autoimmune and Musculoskeletal Disease, Feinstein Institute for Medical Research, 350 Community Drive, Manhasset, New York 11030, USA. Phone: 516.562.3830; E-mail bdiamond@nshs.edu.
1. Robbins WC, Holman HR, Deicher H, Kunkel HG. Complement fixation with cell nuclei and DNA in lupus erythematosus. Proc Soc Exp Biol Med.1957;96(3):575-579.

2. Miescher P, Fauconnet M. [Absorption of L. E. factor by isolated cell nuclei]. Experientia. 1954;10(6):252-253.

3. Mackay IR. Travels and travails of autoimmunity: a historical journey from discovery to rediscovery. Autoimmun Rev. 2010;9(5):A251-A258.

4. Loder F, et al. B cell development in the spleen takes place in discrete steps and is determined by the quality of B cell receptor-derived signals. JExp Med.1999;190(1):75-89.

5. Rice JS, Newman J, Wang C, Michael DJ, Diamond B. Receptor editing in peripheral B cell tolerance. Proc Natl Acad Sci US A.
2005;102(5):1608-1613.

6. Pulendran B, Kannourakis G, Nouri S, Smith KG, Nossal GJ. Soluble antigen can cause enhanced apoptosis of germinal-centre B cells. Nature. 1995;375(6529):331-334.

7. Wardemann H, Yurasov S, Schaefer A, Young JW, Meffre E, Nussenzweig MC. Predominant autoantibody production by early human B cell precursors. Science. 2003;301(5638):1374-1377.

8. Pao LI, et al. B cell-specific deletion of proteintyrosine phosphatase Shp1 promotes B-1a cell development and causes systemic autoimmunity. Immunity. 2007;27(1):35-48.

9. Thien M, et al. Excess BAFF rescues self-reactive B cells from peripheral deletion and allows them to enter forbidden follicular and marginal zone niches. Immunity. 2004;20(6):785-798.
10. Batten M, et al. BAFF mediates survival of peripheral immature B lymphocytes. J Exp Med. 2000;192(10):1453-1466.

11. Samuels J, Ng YS, Coupillaud C, Paget D, Meffre E. Impaired early B cell tolerance in patients with rheumatoid arthritis. J Exp Med. 2005;201(10):1659-1667.

12. Yurasov S, et al. Defective B cell tolerance checkpoints in systemic lupus erythematosus. J Exp Med. 2005;201(5):703-711.

13. Giles IP, Haley JD, Nagl S, Isenberg DA, Latchman DS, Rahman A. A systematic analysis of sequences of human antiphospholipid and anti- $\beta 2$-glycoprotein I antibodies: the importance of somatic mutations and certain sequence motifs. Semin Arthritis Rheum. 2003;32(4):246-265. 
14. Schroder AE, Greiner A, Seyfert C, Berek C. Differentiation of $\mathrm{B}$ cells in the nonlymphoid tissue of the synovial membrane of patients with rheumatoid arthritis. Proc Natl Acad Sci U S A. 1996;93(1):221-225.

15. Carayannopoulos MO, Potter KN, Li Y, Natvig JB, Capra JD. Evidence that human immunoglobulin M rheumatoid factors can Be derived from the natural autoantibody pool and undergo an antigen driven immune response in which somatically mutated rheumatoid factors have lower affinities for immunoglobulin G Fc than their germline counterparts. Scand J Immunol. 2000;51(4):327-336.

16. Diamond B, Scharff MD. Somatic mutation of the T15 heavy chain gives rise to an antibody with autoantibody specificity. Proc Natl Acad Sci U S A. 1984;81(18):5841-5844.

17. Mietzner B, et al. Autoreactive IgG memory antibodies in patients with systemic lupus erythematosus arise from nonreactive and polyreactive precursors. Proc Natl Acad Sci U S A. 2008;105(28):9727-9732.

18. Amara K, et al. Monoclonal IgG antibodies generated from joint-derived $B$ cells of RA patients have a strong bias toward citrullinated autoantigen recognition. JExp Med. 2013;210(3):445-455.

19. Wellmann U, Letz M, Herrmann M, Angermuller S, Kalden JR, Winkler TH. The evolution of human anti-double-stranded DNA autoantibodies. Proc Natl Acad Sci U S A. 2005;102(26):9258-9263.

20. Morris DL, et al. MHC associations with clinical and autoantibody manifestations in European SLE. Genes Immun. 2014;15(4):210-217.

21. Irigoyen $\mathrm{P}$, et al. Regulation of anti-cyclic citrullinated peptide antibodies in rheumatoid arthritis: contrasting effects of HLA-DR3 and the shared epitope alleles. Arthritis Rheum. 2005;52(12):3813-3818.

22. Scally SW, et al. A molecular basis for the association of the HLA-DRB1 locus, citrullination, and rheumatoid arthritis. J Exp Med. 2013;210(12):2569-2582.

23. Mohan C, Adams S, Stanik V, Datta SK. Nucleosome: a major immunogen for pathogenic autoantibody-inducing T cells of lupus. J Exp Med. 1993;177(5):1367-1381.

24. Rekvig OP, et al. Experimental expression in mice and spontaneous expression in human SLE of polyomavirus T-antigen. A molecular basis for induction of antibodies to DNA and eukaryotic transcription factors. JClin Invest. 1997;99(8):2045-2054.

25. Kaliyaperumal A, Mohan C, Wu W, Datta SK. Nucleosomal peptide epitopes for nephritisinducing T helper cells of murine lupus. J Exp Med.1996;183(6):2459-2469.

26. Desai-Mehta A, Mao C, Rajagopalan S, Robinson T, Datta SK. Structure and specificity of T cell receptors expressed by potentially pathogenic anti-DNA autoantibody-inducing $\mathrm{T}$ cells in human lupus. JClin Invest. 1995;95(2):531-541.

27. Ray SK, Putterman C, Diamond B. Pathogenic autoantibodies are routinely generated during the response to foreign antigen: a paradigm for autoimmune disease. Proc Natl Acad Sci U S A. 1996;93(5):2019-2024.

28. Kain R, et al. Molecular mimicry in pauci- immune focal necrotizing glomerulonephritis. Nat Med. 2008;14(10):1088-1096.

29. McClain MT, Heinlen LD, Dennis GJ, Roebuck J, Harley JB, James JA. Early events in lupus humoral autoimmunity suggest initiation through molecular mimicry. Nat Med. 2005;11(1):85-89.

30. Kinloch AJ, et al. Immunization with Porphyromonas gingivalis enolase induces autoimmunity to mammalian alpha-enolase and arthritis in DR4-IE-transgenic mice. Arthritis Rheum. 2011;63(12):3818-3823.

31. Galvin JE, Hemric ME, Ward K, Cunningham MW. Cytotoxic mAb from rheumatic carditis recognizes heart valves and laminin. J Clin Invest. 2000;106(2):217-224.

32. Humby F, et al. Ectopic lymphoid structures support ongoing production of class-switched autoantibodies in rheumatoid synovium. PLoS Med. 2009;6(1):e1.

33. Salomonsson S, et al. Cellular basis of ectopic germinal center formation and autoantibody production in the target organ of patients with Sjogren's syndrome. Arthritis Rheum. 2003;48(11):3187-3201.

34. Willemze A, et al. The ACPA recognition profile and subgrouping of ACPA-positive RA patients. Ann Rheum Dis. 2012;71(2):268-274.

35. Pratesi F, et al. Antibodies from patients with rheumatoid arthritis target citrullinated histone 4 contained in neutrophils extracellular traps. Ann Rheum Dis. 2014;73(7):1414-1422.

36. Furnrohr BG, Groer GJ, Sehnert B, Herrmann $\mathrm{M}$, Voll RE. Interaction of histones with phospholipids -implications for the exposure of histones on apoptotic cells. Autoimmunity. 2007;40(4):322-326.

37. Radic M, Marion T, Monestier M. Nucleosomes are exposed at the cell surface in apoptosis. JImmunol. 2004;172(11):6692-6700.

38. Hong Y, et al. Anti-neutrophil cytoplasmic antibodies stimulate release of neutrophil microparticles. J Am Soc Nephrol. 2012;23(1):49-62.

39. Kantari C, et al. Proteinase 3 , the Wegener autoantigen, is externalized during neutrophil apoptosis: evidence for a functional association with phospholipid scramblase 1 and interference with macrophage phagocytosis. Blood. 2007;110(12):4086-4095.

40. Dwivedi N, Radic M. Citrullination of autoantigens implicates NETosis in the induction of autoimmunity. Ann Rheum Dis. 2014;73(3):483-491.

41. Dieker JW, et al. Apoptosis-induced acetylation of histones is pathogenic in systemic lupus erythematosus. Arthritis Rheum. 2007;56(6):1921-1933.

42. Huynh ML, Fadok VA, Henson PM. Phosphatidylserine-dependent ingestion of apoptotic cells promotes TGF- $\beta 1$ secretion and the resolution of inflammation. JClin Invest. 2002;109(1):41-50.

43. Truedsson L, Bengtsson AA, Sturfelt G. Complement deficiencies and systemic lupus erythematosus. Autoimmunity. 2007;40(8):560-566.

44. Budhai L, Oh K, Davidson A. An in vitro assay for detection of glomerular binding IgG autoantibodies in patients with systemic lupus erythematosus. JClin Invest. 1996;98(7):1585-1593.

45. Putterman C, Limpanasithikul W, Edelman M, Diamond B. The double edged sword of the immune response: mutational analysis of a murine anti-pneumococcal, anti-DNA antibody. JClin Invest. 1996;97(10):2251-2259.

46. Franchin G, Son M, Kim SJ, Ben-Zvi I, Zhang J, Diamond B. Anti-DNA antibodies cross-react with C1q. J Autoimmun. 2013;44:34-39.

47. Krishnan MR, Wang C, Marion TN. Anti-DNA autoantibodies initiate experimental lupus nephritis by binding directly to the glomerular basement membrane in mice. Kidney Int . 2012;82(2):184-192.

48. Kalaaji M, et al. Glomerular apoptotic nucleosomes are central target structures for nephritogenic antibodies in human SLE nephritis. Kidney Int. 2007;71(7):664-672.

49. Mjelle JE, Rekvig OP, Van Der Vlag J, Fenton KA. Nephritogenic antibodies bind in glomeruli through interaction with exposed chromatin fragments and not with renal cross-reactive antigens. Autoimmunity. 2011;44(5):373-383.

50. Ioan-Facsinay A, et al. Anti-cyclic citrullinated peptide antibodies are a collection of anti-citrullinated protein antibodies and contain overlapping and non-overlapping reactivities. Ann Rheum Dis. 2011;70(1):188-193.

51. Sokolove J, Zhao X, Chandra PE, Robinson WH. Immune complexes containing citrullinated fibrinogen costimulate macrophages via Toll-like receptor 4 and $\mathrm{Fc} \gamma$ receptor. Arthritis Rheum. 2011;63(1):53-62.

52. Zhang P, Cox CJ, Alvarez KM, Cunningham MW. Cutting edge: cardiac myosin activates innate immune responses through TLRs. Jimmunol. 2009;183(1):27-31.

53. Horkko S, Miller E, Branch DW, Palinski W, Witztum JL. The epitopes for some antiphospholipid antibodies are adducts of oxidized phospholipid and $\beta 2$ glycoprotein 1 (and other proteins). Proc Natl Acad Sci US A. 1997;94(19):10356-10361.

54. Imai $Y$, et al. Identification of oxidative stress and Toll-like receptor 4 signaling as a key pathway of acute lung injury. Cell. 2008;133(2):235-249.

55. Zhou R, Yazdi AS, Menu P, Tschopp J. A role for mitochondria in NLRP3 inflammasome activation. Nature. 2011;469(7329):221-225.

56. Iyer SS, et al. Mitochondrial cardiolipin is required for Nlrp3 inflammasome activation. Immunity. 2013;39(2):311-323.

57. Ehlers M, Fukuyama H, McGaha TL, Aderem A, Ravetch JV. TLR9/MyD88 signaling is required for class switching to pathogenic IgG2a and $2 \mathrm{~b}$ autoantibodies in SLE. J Exp Med. 2006;203(3):553-561.

58. Christensen SR, Shupe J, Nickerson K, Kashgarian M, Flavell RA, Shlomchik MJ. Toll-like receptor 7 and TLR9 dictate autoantibody specificity have opposing inflammatory regulatory roles in a murine model of lupus. Immunity. 2006;25(3):417-428.

59. Hua Z, et al. Requirement for MyD88 signaling in $B$ cells and dendritic cells for germinal center anti-nuclear antibody production in Lyn-deficient mice. J Immunol. 2014;192(3):875-885.

60. Groom JR, et al. BAFF and MyD88 signals promote a lupuslike disease independent of T cells. JExp Med. 2007;204(8):1959-1971.

61. Lau CM, et al. RNA-associated autoantigens activate $\mathrm{B}$ cells by combined $\mathrm{B}$ cell antigen recep- 
tor/Toll-like receptor 7 engagement. J Exp Med. 2005;202(9):1171-1177.

62. Viglianti GA, Lau CM, Hanley TM, Miko BA, Shlomchik MJ, Marshak-Rothstein A. Activation of autoreactive B cells by $\mathrm{CpG}$ dsDNA. Immunity. 2003;19(6):837-847.

63. Chaturvedi A, Dorward D, Pierce SK. The B cell receptor governs the subcellular location of Toll-like receptor 9 leading to hyperresponses to DNA-containing antigens. Immunity. 2008;28(6):799-809.

64. Aranburu A, Ceccarelli S, Giorda E, Lasorella $\mathrm{R}$, Ballatore $\mathrm{G}$, Carsetti R. TLR ligation triggers somatic hypermutation in transitional B cells inducing the generation of IgM memory B cells. JImmunol. 2010;185(12):7293-7301.

65. Giltiay NV, et al. Overexpression of TLR7 promotes cell-intrinsic expansion and autoantibody production by transitional T1 B cells. J Exp Med. 2013;210(12):2773-2789.

66. Azulay-Debby H, Edry E, Melamed D. CpG DNA stimulates autoreactive immature $B$ cells in the bone marrow. Eur J Immunol. 2007;37(6):1463-1475.

67. Bernasconi NL, Onai N, Lanzavecchia A. A role for Toll-like receptors in acquired immunity: up-regulation of TLR9 by BCR triggering in naive $\mathrm{B}$ cells constitutive expression in memory B cells. Blood. 2003;101(11):4500-4504.

68. Bourke E, Bosisio D, Golay J, Polentarutti N, Mantovani A. The toll-like receptor repertoire of human B lymphocytes: inducible and selective expression of TLR9 and TLR10 in normal transformed cells. Blood. 2003;102(3):956-963.

69. Good KL, Avery DT, Tangye SG. Resting human memory B cells are intrinsically programmed for enhanced survival and responsiveness to diverse stimuli compared to naive B cells. JImmunol. 2009;182(2):890-901.

70. Meyer-Bahlburg A, Khim S, Rawlings DJ. $B$ cell intrinsic TLR signals amplify but are not required for humoral immunity. J Exp Med. 2007;204(13):3095-3101.

71. Herlands RA, Christensen SR, Sweet RA, Hershberg U, Shlomchik MJ. T cell-independent and toll-like receptor-dependent antigen-driven activation of autoreactive B cells. Immunity. 2008;29(2):249-260.

72. Bombardieri M, et al. A BAFF/APRIL-dependent TLR3-stimulated pathway enhances the capacity of rheumatoid synovial fibroblasts to induce AID expression and Ig class-switching in B cells. Ann Rheum Dis. 2011;70(10):1857-1865.

73. Puga I, et al. B cell-helper neutrophils stimulate the diversification and production of immunoglobulin in the marginal zone of the spleen. Nat Immunol. 2012;13(2):170-180.

74. Genestier L, Taillardet M, Mondiere P, Gheit H, Bella C, Defrance T. TLR agonists selectively promote terminal plasma cell differentiation of $B$ cell subsets specialized in thymus-independent responses. JImmunol. 2007;178(12):7779-7786.

75. Pone EJ, et al. BCR-signalling synergizes with TLR-signalling for induction of AID and immunoglobulin class-switching through the non-canonical NF-kB pathway. Nat Commun . 2012;3:767.

76. Jiang W, Lederman MM, Harding CV, Rodriguez
B, Mohner RJ, Sieg SF. TLR9 stimulation drives naive $B$ cells to proliferate to attain enhanced antigen presenting function. Eur J Immunol. 2007;37(8):2205-2213.

77. Boeglin E, Smulski CR, Brun S, Milosevic S, Schneider P, Fournel S. Toll-like receptor agonists synergize with CD4OL to induce either proliferation or plasma cell differentiation of mouse B cells. PLoS One. 2011;6(10):e25542.

78. Gaynor B, Putterman C, Valadon P, Spatz L, Scharff MD, Diamond B. Peptide inhibition of glomerular deposition of an anti-DNA antibody. Proc Natl Acad Sci U S A. 1997;94(5):1955-1960.

79. Raz E, Brezis M, Rosenmann E, Eilat D. Anti-DNA antibodies bind directly to renal antigens and induce kidney dysfunction in the isolated perfused rat kidney. J Immunol. 1989;142(9):3076-3082.

80. Kuhn KA, et al. Antibodies against citrullinated proteins enhance tissue injury in experimental autoimmune arthritis. JClin Invest. 2006;116(4):961-973.

81. Uysal $\mathrm{H}$, et al. Structure and pathogenicity of antibodies specific for citrullinated collagen type II in experimental arthritis. JExp Med 2009;206(2):449-462.

82. Samarkos M, Davies KA, Gordon C, Loizou S. Clinical significance of IgA anticardiolipin and anti- $\beta 2-G P 1$ antibodies in patients with systemic lupus erythematosus primary antiphospholipid syndrome. Clin Rheumatol. 2006;25(2):199-204

83. Charles N, Hardwick D, Daugas E, Illei GG, Rivera J. Basophils and the $\mathrm{T}$ helper 2 environment can promote the development of lupus nephritis. Nat Med.2010;16(6):701-707.

84. Dema B, et al. Immunoglobulin E plays an immunoregulatory role in lupus. J Exp Med 2014;211(11):2159-2168.

85. Vas J, Gronwall C, Marshak-Rothstein A, Silverman GJ. Natural antibody to apoptotic cell membranes inhibits the proinflammatory properties of lupus autoantibody immune complexes. Arthritis Rheum. 2012;64(10):3388-3398.

86. Son M, Santiago-Schwarz F, Al-Abed Y, Diamond B. C1q limits dendritic cell differentiation and activation by engaging LAIR-1. Proc Natl Acad Sci US A. 2012;109(46):E3160-E3167.

87. Boes M, Schmidt T, Linkemann K, Beaudette BC Marshak-Rothstein A, Chen J. Accelerated development of IgG autoantibodies and autoimmune disease in the absence of secreted IgM. Proc Natl Acad Sci U S A. 2000;97(3):1184-1189.

88. Zhao X, et al. Circulating immune complexes contain citrullinated fibrinogen in rheumatoid arthritis. Arthritis Res Ther. 2008;10(4):R94.

89. Trouw LA, et al. Anti-cyclic citrullinated peptide antibodies from rheumatoid arthritis patients activate complement via both the classical and alternative pathways. Arthritis Rheum. 2009;60(7):1923-1931.

90. Ceribelli A, et al. Complement cascade in systemic lupus erythematosus: analyses of the three activation pathways. Ann N Y Acad Sci. 2009;1173:427-434.

91. Romero V, et al. Immune-mediated poreforming pathways induce cellular hypercitrullination and generate citrullinated autoantigens in rheumatoid arthritis. Sci Transl Med. 2013;5(209):209ra150.

92. Lovgren T, Eloranta ML, Bave U, Alm GV, Ronnblom L. Induction of interferon- $\alpha$ production in plasmacytoid dendritic cells by immune complexes containing nucleic acid released by necrotic or late apoptotic cells and lupus IgG. Arthritis Rheum. 2004;50(6):1861-1872.

93. Clavel C, et al. Induction of macrophage secretion of tumor necrosis factor $\alpha$ through Fc $\gamma$ receptor IIa engagement by rheumatoid arthritisspecific autoantibodies to citrullinated proteins complexed with fibrinogen. Arthritis Rheum. 2008;58(3):678-688.

94. Suurmond J, et al. Toll-like receptor triggering augments activation of human mast cells by anti-citrullinated protein antibodies [published online ahead of print May 12, 2014]. Ann Rheum Dis. doi:10.1136/annrheumdis-2014-205562.

95. Clynes R, Dumitru C, Ravetch JV. Uncoupling of immune complex formation and kidney damage in autoimmune glomerulonephritis. Science. 1998;279(5353):1052-1054.

96. Park SY, et al. Resistance of Fc receptor-deficien mice to fatal glomerulonephritis. JClin Invest. 1998;102(6):1229-1238

97. Sokolove J, et al. Rheumatoid factor as a potentiator of anti-citrullinated protein antibodymediated inflammation in rheumatoid arthritis. Arthritis Rheumatol. 2014;66(4):813-821.

98. Ronnelid J, et al. Longitudinal analysis of citrullinated protein/peptide antibodies (anti-CP) during 5 year follow up in early rheumatoid arthritis: anti-CP status predicts worse disease activity greater radiological progression. Ann Rheum Dis. 2005;64(12):1744-1749.

99. Rantapaa-Dahlqvist S, et al. Antibodies against cyclic citrullinated peptide and IgA rheumatoid factor predict the development of rheumatoid arthritis. Arthritis Rheum. 2003;48(10):2741-2749.

100.Arbuckle MR, et al. Development of autoantibodies before the clinical onset of systemic lupus erythematosus. NEnglJMed. 2003;349(16):1526-1533.

101.Verpoort KN, et al. Isotype distribution of anticyclic citrullinated peptide antibodies in undifferentiated arthritis and rheumatoid arthritis reflects an ongoing immune response. Arthritis Rheum. 2006;54(12):3799-3808.

102. Suwannalai $P$, et al. Avidity maturation of anticitrullinated protein antibodies in rheumatoid arthritis. Arthritis Rheum. 2012;64(5):1323-1328.

103. Rombouts $Y$, et al. Anti-citrullinated protein antibodies acquire a pro-inflammatory Fc glycosylation phenotype prior to the onset of rheumatoid arthritis. Ann Rheum Dis. 2015;74(1):234-241.

104.Ioan-Facsinay A, et al. Marked differences in fine specificity and isotype usage of the anti-citrullinated protein antibody in health and disease. Arthritis Rheum. 2008;58(10):3000-3008.

105. van de Stadt LA, et al. Development of the anti-citrullinated protein antibody repertoire prior to the onset of rheumatoid arthritis. Arthritis Rheum. 2011;63(11):3226-3233.

106.Casciola-Rosen L, et al. Enhanced autoantigen expression in regenerating muscle cells in idiopathic inflammatory myopathy. J Exp Med. 2005;201(4):591-601.

107. Sangaletti S, et al. Neutrophil extracellular traps mediate transfer of cytoplasmic neutrophil anti- 
gens to myeloid dendritic cells toward ANCA

induction and associated autoimmunity. Blood. 2012;120(15):3007-3018.

108. Khandpur R, et al. NETs are a source of citrullinated autoantigens and stimulate inflammatory responses in rheumatoid arthritis. Sci Transl Med. 2013;5(178):178ra140.
109. Hakkim A, et al. Impairment of neutrophil extracellular trap degradation is associated with lupus nephritis. Proc Natl Acad Sci U S A. 2010;107(21):9813-9818.

110. Vogelpoel LT, et al. Fc gamma receptor-TLR cross-talk elicits pro-inflammatory cytokine production by human M2 macrophages. Nat
Commun. 2014;5:5444.

111. Suurmond J, Stoop JN, Rivellese F, Bakker AM, Huizinga TW, Toes RE. Activation of human basophils by combined toll-like receptor- and FceRI-triggering can promote Th2 skewing of naive Thelper cells. Eur J Immunol. 2014;44(2):386-396. 